\title{
Visceral Hypersensitivity and Altered Colonic Motility in Type 2 Diabetic Rat
}

\author{
Tae Sik Sung, ${ }^{1}$ Jun-Ho La, ${ }^{2}$ Tong Mook Kang, ${ }^{3}$ Tae Wan Kim, ${ }^{4 *}$ and II-Suk Yang ${ }^{5 *}$ \\ ${ }^{1}$ Department of Physiology and Cell Biology, University of Nevada School of Medicine, Reno, NV, USA; ${ }^{2}$ Center for Pain Research, Department of \\ Anesthesiology, University of Pittsburgh School of Medicine, Pittsburgh, PA, USA; ${ }^{3}$ Department of Physiology, Sungkyunkwan University School \\ of Medicine, Suwon, Gyeonggi-do, Korea; ${ }^{4}$ Department of Veterinary Physiology, College of Veterinary Medicine, Kyungpook National University, \\ Daegu, Korea; and ${ }^{5}$ Department of Veterinary Physiology, College of Veterinary Medicine, Seoul National University, Seoul, Korea
}

\section{Background/Aims}

Abnormal visceral sensitivity and disordered motility are common in patients with diabetes mellitus. The purpose of the present study was to investigate whether visceral sensation and bowel motility were altered in a rat model of type 2 diabetes mellitus accompanied by weight loss.

\section{Methods}

A type 2 diabetic rat model in adulthood was developed by administrating streptozotocin (STZ; $90 \mathrm{mg} / \mathrm{kg}$, i.p.) to neonatal rats. Eight weeks after STZ administration, rats with blood glucose level of $200 \mathrm{mg} / \mathrm{dL}$ or higher were selected and used as diabetic group $(n=35)$ in this study. Abdominal withdrawal reflex and arterial pulse rate were measured to examine visceral nociception induced by colorectal distension (0.1-1.0 mL). The amplitude, frequency, and area under the curve (AUC) of spontaneous phasic contractions of colonic circular muscles were recorded in vitro to examine colonic motility.

\section{Results}

STZ-treated diabetic rats gained significantly less weight for 8 weeks than control $(P<0.01)$. Forty-eight percent of the diabetic rats showed enhanced visceral nociceptive response to colorectal distension. Diabetic rats did not differ from control rats in colorectal compliance. However, the frequency and AUC, not the amplitude, of colonic spontaneous contraction in vitro was significantly decreased in diabetic rats compared to control rats $(P<0.01$ in frequency and $P<0.05$ in AUC).

\section{Conclusions}

These results demonstrate visceral hypersensitivity and colonic dysmotility in a rat model of type 2 diabetes mellitus accompanied by weight loss.

(J Neurogastroenterol Motil 2015;21:581-588)

\section{Key Words}

Abdominal withdrawal reflex; Colonic dysmotility; Colorectal distension; Diabetes mellitus, type 2; Visceral hypersensitivity

Received: April 1, 2015 Revised: June 23, 2015 Accepted: June 30, 2015

(c) This is an Open Access article distributed under the terms of the Creative Commons Attribution Non-Commercial License (http://creativecommons. org/licenses/by-nc/4.0) which permits unrestricted non-commercial use, distribution, and reproduction in any medium, provided the original work is properly cited.

*Correspondence: Tae wan Kim and II-Suk Yang are equally responsible for this study.

Tae Wan Kim, DVM, PhD

Department of Veterinary Physiology, College of Veterinary Medicine, Kyungpook National University, 80, Daehak-ro, Buk-gu, Daegu 41566, Korea

Tel: +82-53-950-7791, Fax: +82-53-950-5955, E-mail: twkim@mail.knu.ac.kr

II-Suk Yang, DVM, PhD

Department of Veterinary Physiology, College of Veterinary Medicine, Seoul National University, 1 Gwanak-ro, Kwanak-gu, Seou 08826 , Korea

Tel: +82-2-880-1261, Fax: +82-2-873-1213, E-mail: isyang@snu.ac.kr

Tae Sik Sung and Jun-Ho La equally contributed to this work.

Financial support: This work was supported by the Korea Research Foundation Grant funded by the Korean Government (MOEHRD)

(KRF-2005-401-E00405).

Conflicts of interest: None.

Author contributions: Tae Sik Sung, basic experiment and analysis of the research data; Jun-Ho La, searching and interpretation of the research data; Tong Mook Kang, interpretation of the research data; Il-Suk Yang and Tae Wan Kim, plan and management of experiment. ORCID: Tae Wan Kim, http://orcid.org/0000-0002-7943-4682. 


\section{Introduction}

Patients with diabetes mellitus often experience gastrointestinal (GI) symptoms, including chronic abdominal pain and altered bowel habits, for which there is no obvious structural cause. $^{1-7}$ The pathogenesis of the GI symptoms in diabetes is not well understood and likely multi-factorial (motor dysfunction, autonomic neuropathy, glycemic control, psychological factors, etc). ${ }^{8}$ Several studies indicate that diabetic neuropathy could account for such abnormalities ${ }^{9-11}$ but only a few studies have addressed changes in the visceral nociceptive function in diabetes.

Dysmotility, delayed transit, and bacterial overgrowth have been observed in the small and large intestines in diabetes. Constipation associated with diabetes is attributed to dysfunction of both enteric autonomic nerves and smooth muscles in the colon. ${ }^{12}$ For example, contractile responses to acetylcholine and substance $\mathrm{P}$ were significantly decreased in longitudinal and circular muscle preparations of the duodenum, jejunum, and ileum but not colon in diabetes, ${ }^{13}$ while colonic peristaltic reflex was enhanced due to impaired enteric nitrergic inhibitory control in spontaneously diabetic rats. ${ }^{14}$

According to the global statistics of diabetes, 382 million people have this disease worldwide, with type 2 diabetes making up about $90 \%$ of the cases. ${ }^{15}$ Despite the high prevalence of type 2 diabetes causing weight loss, many studies have used animal models of type 1 diabetes or obese models of type 2 diabetes. Here we examined whether abdominal pain and altered bowel habits in diabetic patients could be recapitulated in a rat model of type 2 diabetes accompanied by "weight loss," which better reflects the clinical condition found in type 2 diabetic patients, after neonatal streptozotocin treatment.

\section{Materials and Methods}

\section{Animals}

Neonatal male Sprague-Dawley rats were housed in a colony room maintained under light/dark cycle (12 hours: 12 hours) with a room temperature of $25 \pm 1^{\circ} \mathrm{C}$ for 8 weeks. Animals were weaned at 24 days. Water and food were available ad libitum. All the experimental protocols in this study were reviewed and approved by the Animal Care and Use Committee at the Seoul National University.

\section{Induction of Type 2 Diabetes Mellitus}

A rat model of type 2 diabetes mellitus in adulthood was produced as previously described. ${ }^{15}$ Specifically, 2 day-old neonates were intraperitoneally injected with $90 \mathrm{mg} / \mathrm{kg}$ streptozotocin (STZ; Sigma, St. Louis, MO, USA) in $0.1 \mathrm{M}$ citrate buffer, $\mathrm{pH}$ 4.5. Controls were injected with the equivalent volume of citrate buffer. To minimize leakage, the injection site was selected to be the dorsal midpoint between pelvis and ribs just to the right of the spine. Eight weeks after STZ administration, blood was collected from tail vein and blood glucose level was measured using Accu-Chek Instant (Roche Diagnostics LTD, Mannheim, Germany). Animals whose blood glucose level was equal to or higher than $200 \mathrm{mg} / \mathrm{dL}$ were selected and used as diabetic rats.

\section{Colorectal Distension Procedure}

Colorectal distension (CRD) was carried out as previously described. ${ }^{16}$ A silicon balloon-urethral catheter (6 Fr; Sewoon Medical Co, Seoul, Korea) was used for this purpose. After an overnight fast, animals were lightly anesthetized with 5\% isoflurane (Forene; Abbott Scandinavia AB, Solna, Sweden), and the catheter was carefully inserted into the rectum until the distal end of the balloon was positioned $2 \mathrm{~cm}$ proximal from the anus, and the catheter was taped to the tail. After this procedure, rats were allowed to recover from the anesthesia for 30 minutes in a transparent cubical box $(20 \times 8 \times 8 \mathrm{~cm})$.

Because visceral hypersensitivity is best elicited by rapid phasic distension, ${ }^{17}$ phasic distension in ascending order $(0.1,0.2$, $0.3,0.4,0.6,0.8$, and $1 \mathrm{~mL}$ ) was applied for 20 seconds at 4-minute intervals. In this experiment, the score of abdominal withdrawal reflex (AWR; $0=$ no behavioral response to CRD, $1=$ brief head movements followed by immobility, $2=$ contraction of abdominal muscle without lifting of abdomen, 3 = lifting of abdomen, and $4=$ body arching and lifting of pelvic structure ${ }^{18}$ ) and a concomitant increase in arterial pulse rate (pseudoaffective autonomic response) were measured simultaneously. The AWR score was assessed by researchers blinded to experimental groups

The overall response to the $\mathrm{CRD}$ was transformed to an area under the curve (AUC) and a difference in visceral sensitivity between 2 groups was examined by comparing their AUC. ${ }^{19}$ To calculate colorectal compliance, we measured intracolorectal pressure at each distension intensity.

\section{Colonic Contraction In Vitro}

Measurement of colonic motility in the present study was 
based on the methods previously described. ${ }^{20}$ Each animal was sacrificed by cervical dislocation and a $2 \mathrm{~cm}$-long distal colonic segment was removed promptly. The segment was suspended in a $20 \mathrm{~mL}$ organ chamber containing oxygenated $\left(95 \% \mathrm{O}_{2}\right.$ and $5 \%$ $\left.\mathrm{CO}_{2}\right)$ Krebs solution maintained at $37^{\circ} \mathrm{C}$. The Krebs solution contained (in $\mathrm{mM}$ ) NaCl 118, $\mathrm{KCl}$ 4.7, $\mathrm{KH}_{2} \mathrm{PO}_{4} 1.2, \mathrm{NaHCO}_{3}$ $25, \mathrm{CaCl}_{2} 2.5$, and glucose 11 . The distal end of the segment was tied around the mouth of a J-shaped glass tube that was connected to a pressure transducer (RP-1500; Narco Bio-systems Inc, Houston, TX, USA).

At least 60 minutes were given to the preparations in the organ chamber before recordings. The colonic segment was longitudinally stretched by loading $1 \mathrm{~g}$ tension and its lumen was filled with Krebs solution $(0.2 \mathrm{~mL} / \mathrm{cm}$ segment length). Circular muscle contractions were detected as changes in intraluminal pressure. ${ }^{21}$ The amplitude, frequency and AUC during $3 \mathrm{mi}-$ nutes recording of spontaneous phasic contractions were measured. At the end of each experiment, high $\mathrm{KCl}(60 \mathrm{mM})$ was administered into the bath to directly depolarize smooth muscle cells to measure myogenic contractility of the colonic segment. The magnitude of tonic contraction by $\mathrm{KCl}$ was normalized by the wet weight of the colonic segment $(\mathrm{mmHg} / \mathrm{g}$ tissue weight).

\section{Statistical Methods}

Data were expressed as mean \pm SEM, with $n$, the number of animals. The difference between 2 groups was statistically analyzed using Mann-Whitney U-test at the $P<0.05$ significance level. The relationship between the AWR score and the extent of pulse rate change was determined by linear regression analysis, and the estimated slope coefficients and intercepts were compared with Student's $t$ test. The intraballoon volume-intracolorectal pressure relationship (colonic compliance) of each group was also analyzed as above.

\section{Results}

\section{Body Weight and Blood Glucose Levels}

In diabetic rats, body weight was significantly lower (231.3 $\pm 4.7 \mathrm{~g}, \mathrm{n}=25)$ than that in control rats $(307.7 \pm 6.6 \mathrm{~g}, \mathrm{n}=25$, $P<0.01$; Fig. 1A) and blood glucose concentration was higher $(417.7 \pm 3.2 \mathrm{mg} / \mathrm{dL}, \mathrm{n}=25)$ than that in control rats $(98.3 \pm$ $6.1 \mathrm{mg} / \mathrm{dL}, \mathrm{n}=25, P<0.01$; Fig. 1B).
A

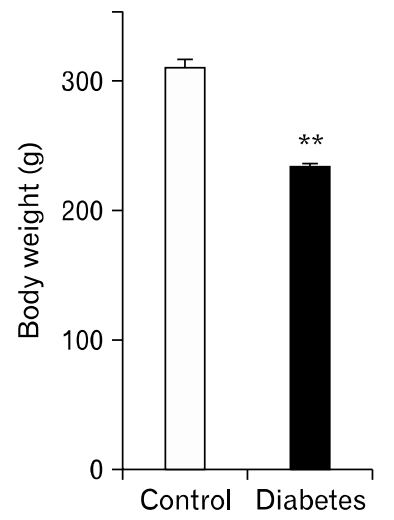

B

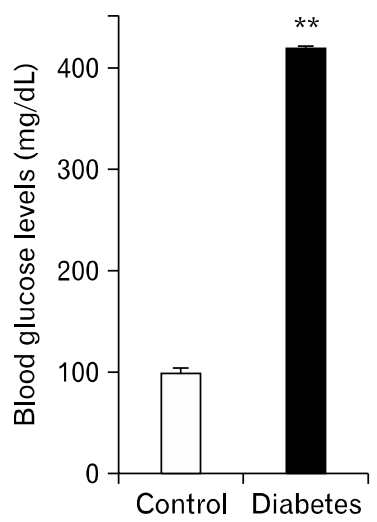

Figure 1. Body weight and blood glucose levels. Body weight (A) and blood glucose levels (B) were measured in 8 week-old control and diabetic rats. Blood was collected from tail vein. Values are mean \pm SEM. ${ }^{* *} P<0.01$ vs control by Mann-Whitney $\mathrm{U}$-test $(\mathrm{n}=25$ in each group).

\section{Visceral Hypersensitivity to Colorectal Distension}

The response patterns to $\mathrm{CRD}$ in control and diabetic rats are shown in Figure 2. Forty-eight percent of diabetic rats showed enhanced visceral nociceptive response to $\mathrm{CRD}$. The AUC was increased from $1.7 \pm 0.1$ to $3.1 \pm 0.1(P<0.01)$ in the AWR score and from $22.9 \pm 3.6$ to $53.7 \pm 5.5(P<0.01)$ in the pulse rate change $(\mathrm{n}=12)$. The pain threshold (distension volume that elicited contraction of abdominal muscle, ie, AWR score 2$)^{16,18}$ was about $0.6 \mathrm{~mL}$ in control rats, but lowered to about $0.2 \mathrm{~mL}$ in diabetic rats. The resting pulse rates were not significantly different between the 2 groups; before the CRD, the pulse rate was $352.1 \pm 3.2(\mathrm{n}=12)$ beat per minute $(\mathrm{BPM})$ in control rats and $349.9 \pm 4.7 \mathrm{BPM}(\mathrm{n}=12)$ in diabetic rats. The hypersensitive diabetic rats did not differ from their normo-sensitive counterpart in body weight and blood glucose level (data now shown).

Because visceral hypersensitivity in diabetic rats could be due to a change in colorectal compliance, the correlation between intraballoon volume and intracolorectal pressure of each group was analyzed by linear regression (Fig. 3A). Intracolorectal pressure was linearly increased as the balloon was inflated $(r>0.99, P<$ 0.001 in control; $r>0.99, P<0.001$ in diabetic rats). Colorectal compliance (the slope of the regression line) was not changed in diabetic rats, suggesting that diabetes did not alter colorectal tone (slope coefficient: $89.6 \pm 6.6$ in control; $87.4 \pm$ 7.3 in diabetic rats $[P>0.05$, d.f. $=10]$, intercept: $-3.4 \pm 1.8$ 
A

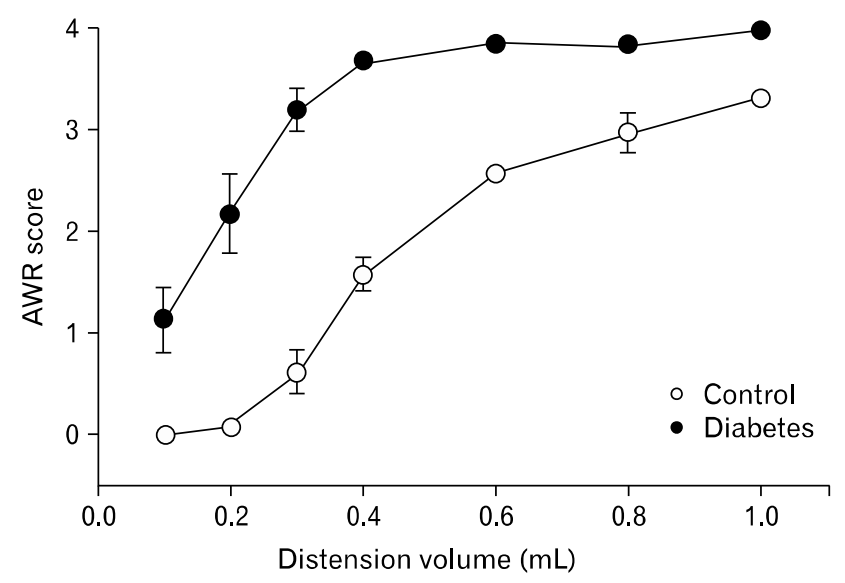

C

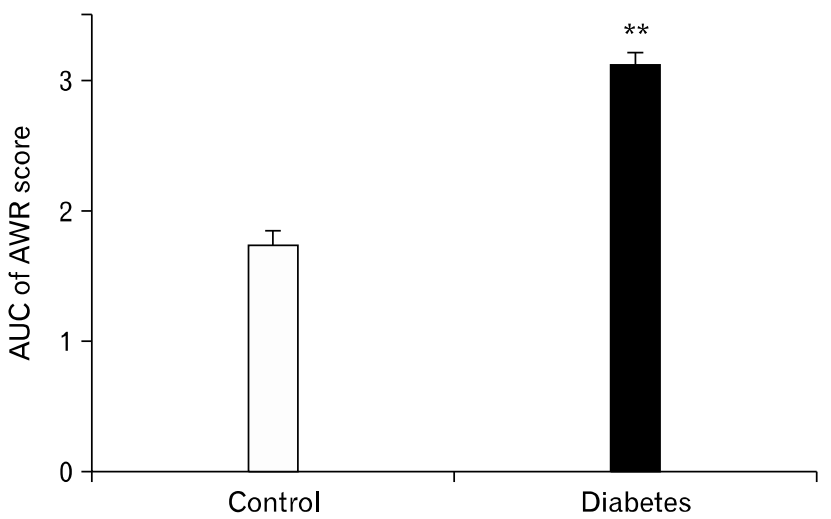

B

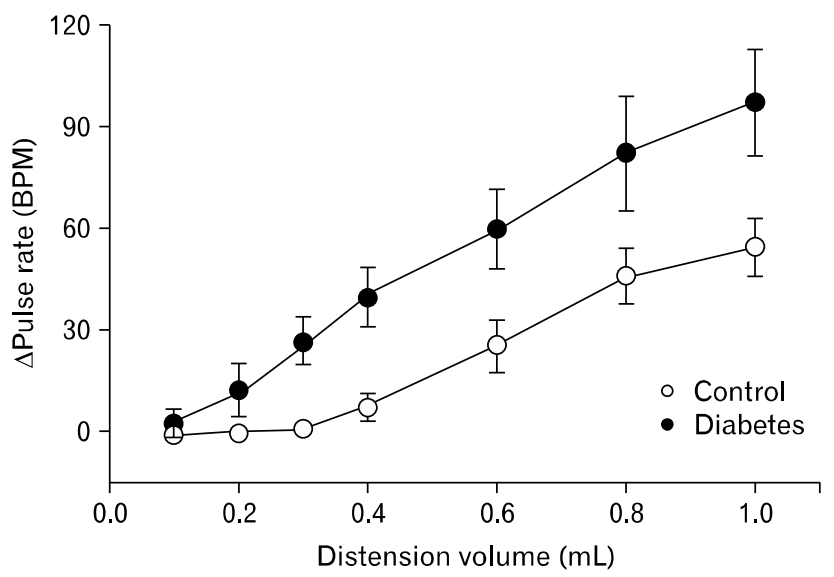

D

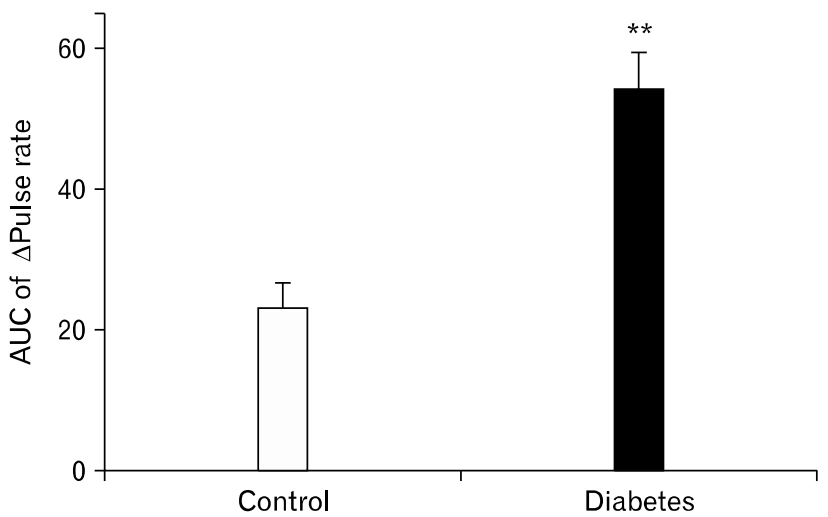

Figure 2. Visceral sensory responses to colorectal distension. Visceral sensory responses were elicited by intracolorectal balloon distension, and quantified by scoring (A) the abdominal withdrawal reflex (AWR) and measuring (B) the increase in arterial pulse rate ( $\Delta$ pulse rate). (C) and (D) represent the area under the curve (AUC) calculated from (A) and (B), respectively. ${ }^{* *} P<0.01$ vs control by Mann-Whitney $\mathrm{U}$-test ( $\mathrm{n}=12 \mathrm{in}$ each group). BPM, beat per minute.

A

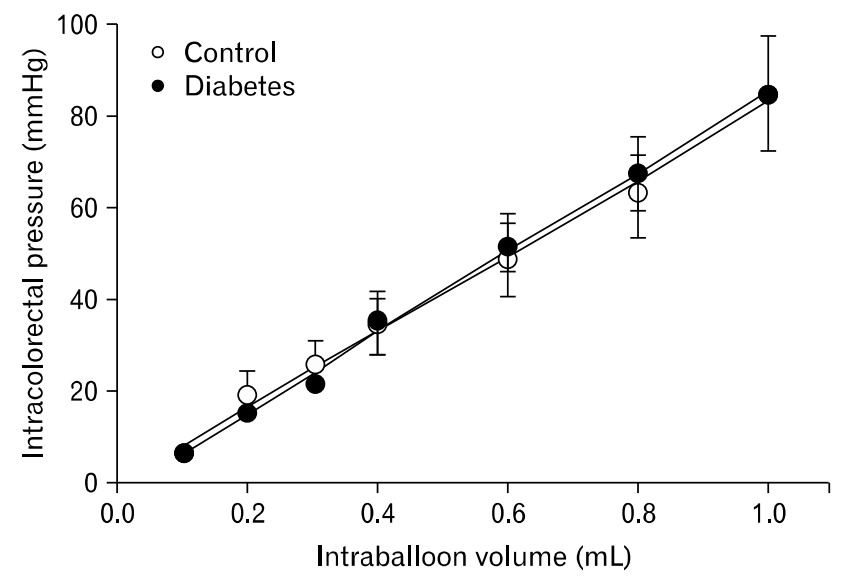

B

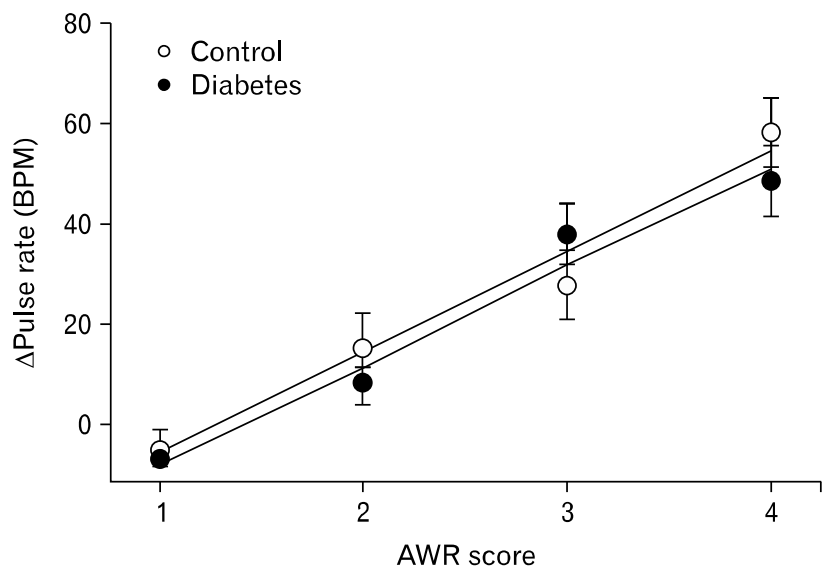

Figure 3. Colorectal compliance and correlation between abdominal withdrawal reflex (AWR) score and pulse rate chages. (A) Colorectal compliance was expressed as a correlation between distension volume and intracolorectal pressure. (B) The correlation between the AWR score and pulse rate was determined by linear regression analysis (each symbol indicates the mean pulse rate at a given AWR score). BPM, beat per minute. 
A

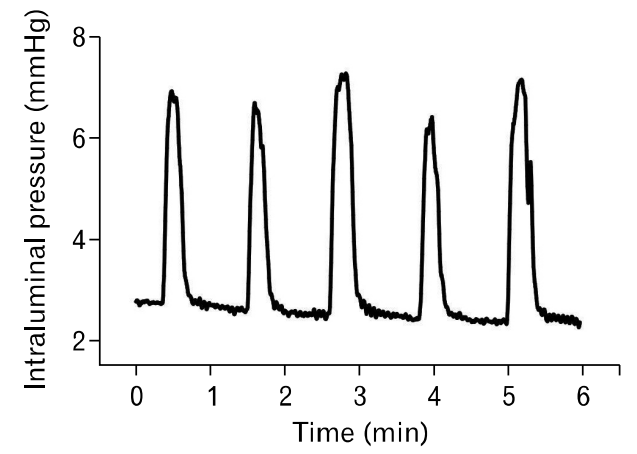

B

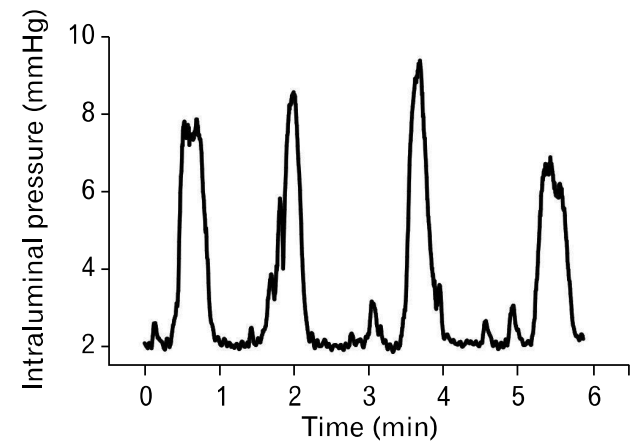

E
C

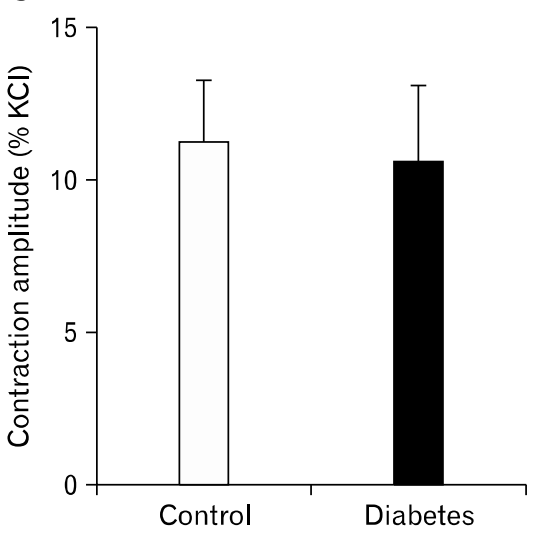

D

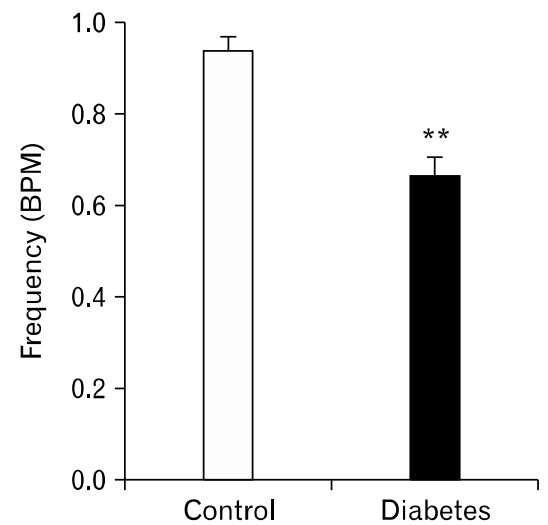

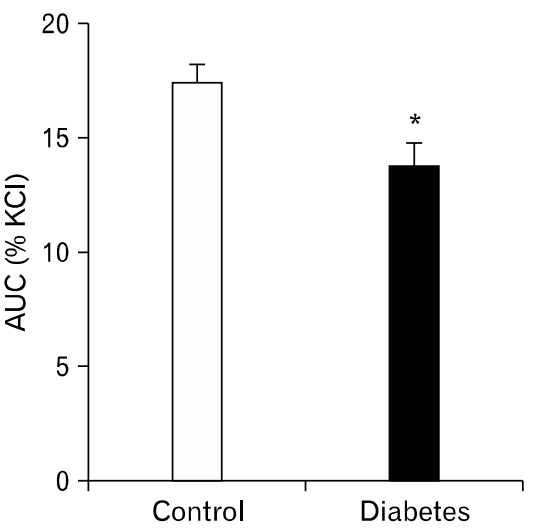

Figure 4. Spontaneous contraction in colonic segments from control and diabetic rats. Mechanical activities of circular muscle were measured as changes in intraluminal pressure in vitro in control (A) and diabetic rats (B). The amplitude of spontaneous contraction was not changed (C), but the frequency and area under the curve (AUC) of spontaneous contraction were significantly decreased in diabetic rats (D\&E). ${ }^{*} P<0.05$ and ${ }^{* *} P<0.01$ vs control by Mann-Whitney U-test ( $\mathrm{n}=6$ in control, $\mathrm{n}=10$ in diabetic rat).

in control; $-2.5 \pm 1.0$ diabetic rats $[P>0.05$, d.f. $=10])$ (Fig. 3A). In addition, the AWR scores were linearly correlated with the pulse rate change $(r>0.98, P=0.011$ in control; $r>$ $0.99, P=0.01$ in diabetic rats) (Fig. 3B). These fitted functions were not significantly different between the 2 groups (slope coefficient: $16.7 \pm 1.5$ in control; $17.3 \pm 2.1$ in diabetic rats $[P>$ 0.05 , d.f. $=4]$, intercept: $-12.7 \pm 1.7$ in control; $-12.0 \pm 4.7$ diabetic $[P>0.05$, d.f. $=4]$ ), indicating that scoring the AWR in the present study was a reliable method to quantify the animal's nociceptive response to $\mathrm{CRD}$ as shown in the previous study. ${ }^{16}$

\section{Spontaneous Phasic Contraction and $\mathrm{KCl}$-induced Tonic Contraction in Isolated Colon In Vitro}

Colonic segments showed spontaneous phasic contractions at rest (Fig. 4A and 4B). The amplitude of these contractions, when normalized to that of $\mathrm{KCl}(60 \mathrm{mM})$-induced tonic contraction, did not differ between the 2 groups; $11.3 \pm 2.0 \%(n=6)$ in control and $10.5 \pm 2.6 \%(\mathrm{n}=10)$ in diabetic group (Fig. $4 \mathrm{C})$. However, the frequency $(0.9 \pm 0.1 \mathrm{BPM}$ in control vs $0.7 \pm 0.1$ BPM in diabetic group, $P<0.01$; Fig. 4D) and AUC $(17.4 \pm$ $0.8 \%$ in control vs $13.6 \pm 1.1 \%$ in diabetic group, $P<0.05$; Fig. $4 \mathrm{E}$ ) of these contractions were significantly reduced in diabetic group.

We examined whether contractility of colonic smooth muscle cells was changed in these rat model of type 2 diabetes by directly triggering excitation-contraction in smooth muscle cells with 60 $\mathrm{mM} \mathrm{KCl}$ (depolarizing smooth muscle membrane potential). There was no difference in the $\mathrm{KCl}$-induced tonic contractions of circular muscle cells (tonic increase in intraluminal pressure) between control and diabetic groups $(2.9 \pm 2.5 \mathrm{mmHg} / \mathrm{g}$ colon in control and $2.6 \pm 3.0 \mathrm{mmHg} / \mathrm{g}$ colon in diabetic group) (Fig. 5). 
A

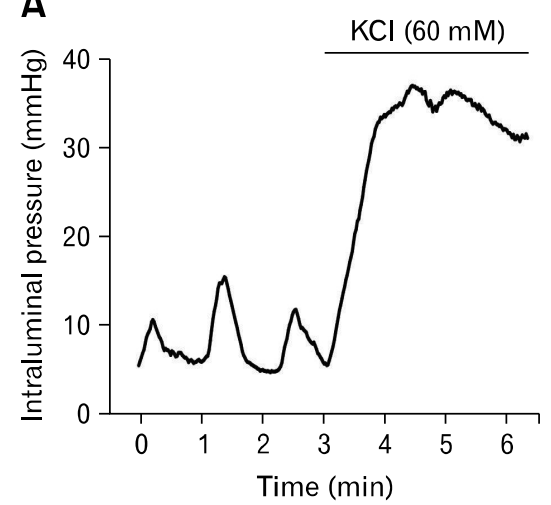

B

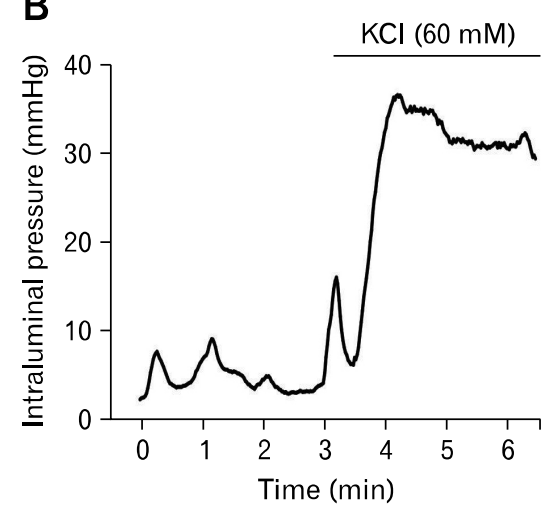

C

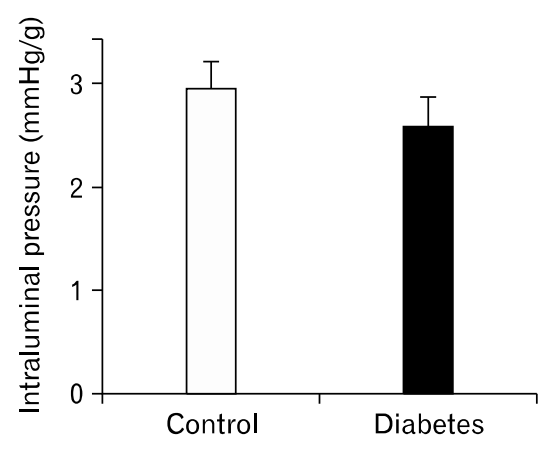

Figure 5. Mechanical activities of isolated colonic segment. Mechanical activities of circular muscle were measured as changes in intraluminal pressure in control (A) and diabetic colon (B). No difference was observed in the $\mathrm{KCl}(60 \mathrm{mM})$-induced tonic contraction between groups (C).

\section{Discussion}

\section{Visceral Sensory Responses to Colorectal Distension}

The results of this study demonstrate that $48 \%$ of type 2 diabetic rats developed visceral hypersensitivity, shown by increased AWR score and the pulse rate change in response to CRD. To our knowledge, this is the first report showing visceral hypersensitivity in rats with type 2 diabetes accompanied by weight loss, which is in accordance with the previous report of increased visceromotor responses to $\mathrm{CRD}$ in type I diabetic rats. ${ }^{22}$ The remaining $52 \%$ of STZ-treated rats in this study did not develop visceral hypersensitivity to CRD even though they did not differ from the hypersensitive rats in body weights, blood glucose levels, and colorectal compliance, suggesting that these 3 physical/physiological factors in diabetes are not the direct cause of visceral hypersensitivity associated with type 2 diabetes. It is unclear why not all STZ-treated diabetic rats developed visceral hypersensitivity inasmuch as what caused visceral hypersensitivity in the $48 \%$ of diabetic rats. Considering that diabetic patients with neuropathy show high prevalence in GI symptoms, ${ }^{4,5}$ the degree and/or sites of neuropathy in STZ-treated rats might account for the presence/absence of visceral hypersensitivity. In this regard, an approach to assess the potential correlation between the 2 pathophysiological outcomes of diabetes (peripheral neuropathy and visceral hypersensitivity) deserves researchers' attention in future studies.

STZ, in a bell-shaped concentration-dependent manner, can directly act on sensory neurons to upregulate transient receptor potential vanilloid type 1 and consequently induce thermal hypersensitivity, ${ }^{23}$ based on which one could speculate that the visceral hypersensitivity in the $48 \%$ of our diabetic rat model might result from STZ-induced sensitization of sensory neurons, not necessarily from STZ-induced diabetes and associated neuropathy. This speculation needs assumptions that the concentration of STZ in sensory ganglia is in the effective dose range (20-200 $\mu \mathrm{M})$ after a single neonatal injection of $90 \mathrm{mg} / \mathrm{kg} \mathrm{STZ}$, and the STZ-induced sensitization of sensory neurons could persist for 8 weeks. Testing these assumptions is beyond the scope of the present study, but it would be interesting to examine whether the $52 \%$ of STZ-treated diabetic rats were normo-sensitive to CRD because of failed persistence of STZ-induced sensitization of sensory neurons. Alternatively, considering that chronic diabetic neuropathy often leads to loss of sensation, one could also postulate that the normo-sensitive diabetic rats might have developed severer diabetic neuropathy that counteracted sensory neuronal sensitization by STZ.

It is also noteworthy that stress and low-grade gut inflammation are considered to trigger visceral pain in functional GI disorder such as irritable bowel syndrome, ${ }^{24,25}$ suggesting the stress response and gut inflammatory states in the hypersensitive diabetic rats could differ from those in their normo-sensitive counterpart.

\section{Reduced Colonic Motility}

Diabetes is associated with a remodeling of the enteric nervous system such as modifications in neuronal morphology and neurotransmitter contents, ultimately changing the function of enteric neurons. These changes in enteric neurons and pacemaking system such as interstitial cells of Cajal (ICC) are likely 
to play a role in alterations in GI motility. ${ }^{26,27}$ GI smooth muscle can also be affected by diabetes. This study shows that myogenic contractility of colonic smooth muscle (excitation-contraction ability of smooth muscle cell itself) was not changed by diabetes. However, in diabetic rats, we observed a decrease in the frequency of spontaneous contractions, suggesting that diabetes-induced changes in enteric nervous system and ICC are the likely candidate of the altered colonic motility in the rat model of type 2 diabetes with weight loss because the spontaneous contractions are controlled by ICC and modulated by enteric neurons. Interfering with nitrergic inhibitory or cholinergic excitatory enteric neurotransmission and ICC is known to affect GI motility in diabetes. ${ }^{13,27,28}$ Therefore, the selective decrease only in the frequency of spontaneous contraction in diabetes could be a net outcome of changes in ICC and multiple enteric neurons counteracting/modulating each other. Although many studies have explored dysmotility in diabetic patients and animal models, ${ }^{29-33}$ the results are inconsistent across the studies because the degree, period, and type of diabetes are different in each study.

In summary, we found that the rat model of STZ-induced type 2 diabetes with weight loss recapitulated 2 features of GI disorders in patients with diabetes mellitus; visceral hypersensitivity and altered colonic motility. A future study needs to examine the causative factors for the 2 symptoms in diabetes with special respect to the degree/sites of neuropathy in sensory and enteric nervous systems.

\section{References}

1. Katz LA, Spiro HM. Gastrointestinal manifestations of diabetes. N Engl J Med 1966;275:1350-1361.

2. Goyal RK, Spiro HM. Gastrointestinal manifestations of diabetes mellitus. Med Clin North Am 1971;55:1031-1044.

3. Locke GR 3rd. Epidemiology of gastrointestinal complications of diabetes mellitus. Eur J Gastroenterol Hepatol 1995;7:711-716.

4. Rundles RW. Diabetic neuropathy. Bull N Y Acad Med 1950;26: 598-616.

5. Hodges FJ, Rundles RW, Hanelin J. Roentgenologic study of the small intestine II. Dysfunction associated with neurologic disease. Radiology 1947;49:659-673.

6. Khoshbaten M, Madad L, Baladast M, Mohammadi M, Aliasgarzadeh A. Gastrointestinal signs and symptoms among persons with diabetes mellitus. Gastroenterol Hepatol Bed Bench 2011;4:219-223.

7. Talley NJ, Young L, Bytzer P, et al. Impact of chronic gastrointestinal symptoms in diabetes mellitus on health-related quality of life. Am J Gastroenterol 2001;96:71-76.

8. Horowitz M, Samsom M. Gastrointestinal function in diabetes mellitus. Chichester: John Wiley \& Sons, Ltd 2004:1-337.

9. Kamath MV, Tougas G, Fitzpatrick D, et al. Assessment of the vis- ceral afferent and autonomic pathways in response to esophageal stimulation in control subjects and in patients with diabetes. Clin Invest Med 1998;21:100-113.

10. Rathmann W, Enck P, Frieling T, Gries FA. Visceral afferent neuropathy in diabetic gastroparesis. Diabetes Care 1991;14:1086-1089.

11. Grabauskas G, Heldsinger A, Wu X, Xu D, Zhou S, Owyang C. Diabetic visceral hypersensitivity is associated with activation of mitogen-activated kinase in rat dorsal root ganglia. Diabetes 2011;60: 1743-1751.

12. Imaeda K, Takano H, Koshita M, Yamamoto Y, Joh T, Suzuki H. Electrical properties of colonic smooth muscle in spontaneously noninsulin-dependent diabetic rats. J Smooth Muscle Res 1998;34:1-11.

13. Liu HS, Karakida T, Homma S. Acetylcholine and substance P responsiveness of intestinal smooth muscles in streptozotocin diabetic rats. Jpn J Physiol 1988;38:787-797.

14. Yoneda S, Kadowaki M, Kuramoto H, Fukui H, Takaki M. Enhanced colonic peristalsis by impairment of nitrergic enteric neurons in spontaneously diabetic rats. Auton Neurosci 2001;92:65-71.

15. Bonner-Weir S, Trent DF, Honey RN, Weir GC. Responses of neonatal rat islets to streptozotocin: limited B-cell regeneration and hyperglycemia. Diabetes 1981;30:64-69.

16. La JH, Kim TW, Sung TS, Kang JW, Kim HJ, Yang IS. Visceral hypersensitivity and altered colonic motility after subsidence of inflammation in a rat model of colitis. World J Gastroenterol 2003;9: 2791-2795.

17. Delvaux M. Role of visceral sensitivity in the pathophysiology of irritable bowel syndrome. Gut 2002;51(suppl 1):i67-i71.

18. Al-Chaer ED, Kawasaki M, Pasricha PJ. A new model of chronic visceral hypersensitivity in adult rats induced by colon irritation during postnatal development. Gastroenterology 2000;119:1276-1285.

19. La JH, Kim TW, Sung TS, Kim HJ, Kim JY, Yang IS. Role of mucosal mast cells in visceral hypersensitivity in a rat model of irritable bowel syndrome. J Vet Sci 2004;5:319-324.

20. La JH, Kim TW, Sung TS, Kim HJ, Kim JY, Yang IS. Increase in neurokinin-1 receptor-mediated colonic motor response in a rat model of irritable bowel syndrome. World J Gastroenterol 2005;11:237-241.

21. Coupar IM, Liu L. A simple method for measuring the effects of drugs on intestinal longitudinal and circular muscle. J Pharmacol Toxicol Methods 1996;36:147-154.

22. Grabauskas G, Heldsinger A, Wu X, Xu D, Zhou S, Owyang C. Diabetic visceral hypersensitivity is associated with activation of mitogen-activated kinase in rat dorsal root ganglia. Diabetes 2011;60: 1743-1751.

23. Pabbidi RM, Cao DS, Parihar A, Pauza ME, Premkumar LS. Direct role of streptozotocin in inducing thermal hyperalgesia by enhanced expression of transient receptor potential vanilloid 1 in sensory neurons. Mol Pharmacol 2008;73:995-1004.

24. Azpiroz F, Bouin M, Camilleri M, et al. Mechanisms of hypersensitivity in IBS and functional disorders. Neurogastroenterol Motil 2007;19:62-88.

25. Talley NJ, Spiller R. Irritable bowel syndrome: a little understood organic bowel disease? Lancet 2002;360:555-564.

26. Chandrasekharan B, Srinivasan S. Diabetes and the enteric nervous system. Neurogastroenterol Motil 2007;19:951-960.

27. He CL, Soffer EE, Ferris CD, Walsh RM, Szurszewski JH, Farrugia G. Loss of interstitial cells of cajal and inhibitory in- 
nervation in insulin-dependent diabetes. Gastroenterology 2001;121: 427-434.

28. Bijender S, Harish D, Rishi S, Patil BM. Effect of vitamine on the impaired gastrointestinal activity of streptozotocin induced diabetic rats. Indian J Pharmacol 2003;35:186-187.

29. Horowitz M, O'Donovan D, Jones KL, Feinle C, Rayner CK, Samsom M. Gastric emptying in diabetes: clinical significance and treatment. Diabet Med 2002;19:177-194.

30. Bertin E, Schneider N, Abdelli N, et al. Gastric emptying is accelerated in obese type 2 diabetic patients without autonomic neuropathy.
Diabetes Metab 2001;27:357-364.

31. Faraj J, Melander O, Sundkvist G, et al. Oesophageal dysmotility, delayed gastric emptying and gastrointestinal symptoms in patients with diabetes mellitus. Diabet Med 2007;24:1235-1239.

32. Xie DP, Li S, Li L, et al. Beta-arrestine 2 is involved in the increased of distal colonic contraction in diabetic rats. Regul Pept 2013;185: 29-33.

33. Kim SJ, Park JH, Song DK, et al. Alterations of colonic contractility in long-term diabetic rat model. J Neurogastroenterol Motil 2011; 17:372-380. 